\title{
Contribuições da ciência política para o campo educacional: o burocrata de nível de rua
}

LOTTA, Gabriela Spanghero. Burocracia e implementação de políticas públicas - os agentes comunitários na estratégia saúde da família. Rio de Janeiro: Editora Fiocruz, 2015.

O livro Burocracia e implementação de políticas públicas - os agentes comunitários na estratégia saúde da família, de Gabriela Lotta é, no Brasil, um estudo pioneiro sobre o papel das burocracias de nível de rua na implementação de políticas públicas. Essa obra representa uma importante contribuição para o estudo de políticas em geral e faz avançar o debate sobre a fase da implementação, dando destaque à atuação discricionária das Burocracias de Nível de Rua (BNR) - termo cunhado por Lipsky (2010) para se referir aos profissionais do Estado que entregam o serviço da política aos cidadãos.

Os estudos sobre a fase da implementação ainda são pouco explorados na literatura brasileira, sobretudo aqueles que enfatizam "as ações do Estado, incluindo novos atores e modelos analíticos" (LOTTA, 2015, p.15). Embora algumas pesquisas já tenham olhado para as burocracias, a partir de diferentes perspectivas, ainda se constata "uma grande lacuna nos estudos empíricos sobre a fase de implementação de políticas e os diversos elementos e fatores que a influenciam" (LOTTA, 2015, p. 16). Essa lacuna é ainda maior quando se refere ao BNR e o exercício da discricionariedade.

Considerando isso, o estudo de Lotta (2015) contribui para a diminuição desse hiato, uma vez que busca compreender a) como os diversos atores envolvidos na fase de implementação da política influenciam seu funcionamento; b) como atuam os BNR; c) quais os fatores que influenciam suas ações e qual a margem de discricionariedade que eles possuem na realização de suas atividades; e d) quais as consequências desses fatores para a implementação da política.

O estudo parte do pressuposto de que vários fatores levam a diferentes formas de implementação e que a implementação de uma política "se dá a partir 
de processos de interação entre os implementadores e os diversos atores envolvidos no processo, como usuários, outros profissionais da política, políticos e outros" (LOTTA, 2015, p.16-17). A análise busca compreender como o BNR constrói suas ações e como os demais atores envolvidos impactam essa construção.

A compreensão dos processos de interação entre BNR e demais atores deve levar em conta o exercício da discricionariedade dos burocratas, bem como as pequenas decisões que tomam nos processos de implementação, que não devem ser encaradas como erros ou desvios, mas sim "como condições a serem introjetadas nas análises e que podem ajudar a entender o que influencia diretamente as escolhas que os burocratas implementadores efetuam e as questões que condicionam sua própria maneira de enxergar as políticas e atuar sobre elas" (LOTTA, 2015, p. 17).

Tomando como objeto de estudo o BNR e o exercício da discricionariedade deles, Lotta (2015) investigou a atuação dos agentes comunitários de saúde (ACS) inseridos no programa Estratégia Saúde da Família (ESF). Esses agentes foram definidos como burocratas implementadores, pois são os "responsáveis por colocar em prática, nos domicílios dos usuários, as ações de atenção básica à saúde" (LOTTA, 2015, p. 18), efetivando, assim, a mediação entre o Estado e a sociedade. A atuação dos ACS foi analisada por meio de duas perspectivas: as práticas realizadas e os estilos de interação estabelecidos com os usuários. Ambas se caracterizam como elementos que delineiam a forma como a política é implementada.

A partir do levantamento das práticas e dos estilos de interação, diversos fatores foram identificados e agrupados em três conjuntos: 1) os organizacionais, referentes à gestão das Unidades Básicas de Saúde (UBS) e ao funcionamento de suas respectivas equipes; 2) os relacionais, ligados às redes sociais que os ACS estabelecem com os demais profissionais e com os beneficiários da política; 3) afiliações e trajetórias desses ACS.

O mapeamento das práticas e dos estilos de interação foi feito com base em investigação qualitativa, de cunho etnográfico. Cada ACS foi acompanhado por cerca de dez dias, observando-se todas as atividades profissionais por ele realizadas: "visitas domiciliares, reuniões e demais ações dentro da UBS, suas 
interações com a equipe, eventos oficiais da prefeitura e encontros da associação dos ACS. Quando possível foram também acompanhadas algumas atividades informais, como festas e encontros na comunidade" (LOTTA, 2015, p. 21). As atividades foram registradas no diário de campo: as falas foram transcritas, e as situações observadas (ações, práticas e interações) foram descritas.

Além do acompanhamento das atividades, foram realizadas também entrevistas com os ACS, com o objetivo de levantar informações sobre suas redes sociais pessoais. As informações são de origem cognitiva, coletadas a partir do entendimento de que os indivíduos têm sobre as redes que constroem. Esse método pode ter um risco de viés, mas, a despeito disso, a investigação optou por utilizá-lo, pois, segundo Lotta (2015, p.22) "os indivíduos utilizam em suas práticas cotidianas as relações da forma que as compreendem, permitindo que as redes construídas sejam fruto do que os indivíduos entendem como tal". Por fim, a pesquisa realizou entrevistas com os usuários da política, com o propósito de captar algumas dimensões de avaliação do serviço do ACS ou alguns aspectos relacionais. A análise desses dados teve uma relevância menor no trabalho, mas é entendido pela própria autora como pertinente, pois fornece elementos para caracterizar formas de comunicação entre ACS e usuário - uma das dimensões que perpassa os estilos de interação.

A Figura 1 apresenta a estrutura analítica da pesquisa, cujo ponto de partida são os fatores organizacionais/institucionais, mapeados a partir do diário de campo. Esses fatores se referem ao trabalho desenvolvido em cada UBS: estrutura da equipe, formas de coordenação, indicações institucionais para construção da ação e questões organizacionais que influenciam a ação dos ACS. A análise dos fatores organizacionais de cada UBS foi realizada de forma comparativa entre elas e articulada à legislação da ESF. Essa estratégia analítica buscou captar decisões que influenciam a atuação dos ACS.

A análise dos fatores relacionais, dos perfis e das afiliações foi feita a partir do levantamento de informações das redes sociais dos ACS. Essas informações foram tratadas a partir de ferramentas específicas que permitiram "comparar as redes dos ACS entre si, ao longo do tempo e entre diferentes UBS, gerando 
algumas conclusões sobre a estrutura relacional que poderia influenciar a atuação dos burocratas no processo de implementação" (LOTTA, 2015, p.25).

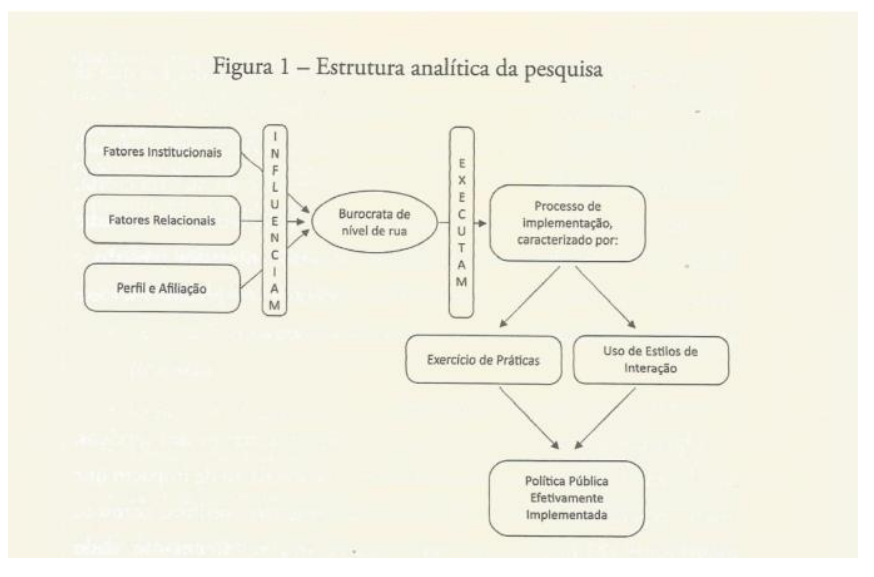

Fonte: Lotta (2015, p.24)

As práticas ${ }^{1}$ e os estilos de interação ${ }^{2}$ foram mapeados nos registros do diário de campo, por meio das observações etnográficas. No total, foram categorizadas 108 práticas diferentes, organizadas em tipos, e 24 estilos de interação, organizados em quatro tipos.

Seguindo a estrutura analítica, o livro está organizado em seis capítulos, além da apresentação, das reflexões finais e dos anexos. O Capítulo 1 apresenta a revisão de literatura sobre a implementação de políticas públicas, definida como o momento em que a política entra em ação e é colocada em prática. No Capítulo 2, Lotta (2015) apresenta o campo e o objeto de estudo e descreve a complexidade dos arranjos institucionais, firmados pelo regime de colaboração para a operacionalização da política. O terceiro capítulo contextualiza os três casos estudados, considerando características da política de saúde em cada município e os fatores organizacionais de cada UBS. O quarto capítulo aborda os fatores relacionais, os perfis e as afiliações da estrutura analítica apresentada na Figura 1. O Capítulo 5 explora o exercício da discricionariedade dos ACS, tomando por base as práticas e os estilos de interação. O Capítulo 6 examina os diversos fatores (organizacionais, relacionais, perfis e afiliações) de forma cruzada, a fim de "compreender o que explica a atuação dos ACS e, portanto, o que influencia a implementação das políticas públicas" (LOTTA, p.29). Por fim,

\footnotetext{
${ }^{1}$ Compreendidas como ações desenvolvidas pelos ACS.

2 Compreendidos como a concretização de como os ACS interagem com os usuários da política.
}

Revista Educação Online, Rio de Janeiro, n. 31, mai-ago 2019, p. 1-9 
nas reflexões finais, são examinadas as consequências da implementação, considerando as principais características do desenho do programa ESF, a atuação dos ACS e as ponderações sobre a análise de políticas públicas.

Essa pesquisa, cuja temática versa sobre a área da saúde, diz respeito ao campo da ciência política, mas sua fundamentação teórica traz valiosas contribuições para o campo da educação.

\section{Reflexões para o campo educacional}

A análise de uma política pública é comumente realizada a partir de um ciclo com quatro fases: agenda, formulação, implementação e avaliação. Poucos estudos na área da educação colocam o foco da análise na fase da implementação. Grande parte dos estudos realizados nesse campo se volta, principalmente, para a fase da formulação - os textos legais e oficiais da política - e para a fase da avaliação, cuja finalidade é verificar os efeitos, ou impactos, que as políticas e os fatores escolares geram sobre o aprendizado dos estudantes.

Esse referencial, provindo da ciência política e cuja ênfase analítica é sobre a fase da implementação, pode contribuir para a compreensão dos efeitos identificados nos estudos de impacto. A partir da análise da atuação dos agentes implementadores e dos processos de implementação de uma determinada política, podem-se identificar elementos discricionários que fazem com que os resultados esperados sejam alcançados, parcialmente alcançados ou não alcançados. A variabilidade dos resultados é explicada pelo exercício da discricionariedade que o agente implementador tem para executar suas tarefas, bem como pelos diferentes processos de implementação estabelecidos.

A fase da implementação é definida, segundo Lotta (2015), como o momento em que a política entra em ação e é colocada em prática. As diferentes concepções sobre como a implementação se dá, considera, dentre outros aspectos, os atores responsáveis pelas tomadas de decisões no processo de implementação. Ou seja, o foco das análises recai sobre a verticalização das decisões: se elas vêm de cima (abordagem top down) ou se são reconstruídas a partir de baixo (abordagem bottom-up). 
O modelo top-down enfatiza a separação entre a política e a administração, tendo como foco analítico o controle e a hierarquia. Trata-se de estipular um ideal normativo para colocar a política em ação. A fase da implementação é encarada como uma "ligação na cadeia causal para obter os resultados desejados" (LOTTA, 2015, p. 37), não havendo espaço para o exercício da discricionariedade, uma vez que os planos devem ser implementados rigorosamente como foram concebidos. Toda e qualquer ação que provoca um resultado diferente do previsto na fase de formulação da política, é encarada como um erro ou um desvio. O modelo bottom-up, por sua vez, parte do pressuposto de que a política é um continuum, em que há modificações no processo de tradução da intenção em ação. Assim, a fase de implementação é permeada por transformações e adaptações.

Se, nos estudos com abordagem top-down, a atenção se volta para as metas e os planos da política, na visão bottom-up, o enfoque é nos processos. Aqui, os resultados de sucesso ou fracasso independem de planos anteriores e são associados aos processos de implementação. A política é encarada como flexível, capaz de se adaptar a contingências e alterações, e é exatamente por causa disso, que resultados diferentes são possíveis.

É a partir da abordagem bottom-up, que o estudo de Lotta (2015) focalizou o papel da burocracia de nível de rua, no processo de implementação da política. Baseando-se em Lipsky (2010), Lotta (2015, p.43) define o BNR como aquele que trabalha diretamente com os usuários ou clientes dos serviços públicos policiais, professores, profissionais da saúde, entre outros. É por meios desses profissionais, que o cidadão acessa a administração pública e os direitos e benefícios governamentais.

Dar ênfase à atuação dos BNR nos estudos sobre implementação é pertinente por duas razões principais. A primeira diz respeito ao debate sobre 0 escopo dos serviços públicos, que são, prioritariamente, concretizados pela atuação dos BNR. Debater esse escopo implica, necessariamente, em debater a função exercida por esses profissionais. A segunda se refere ao impacto que esses burocratas têm na vida das pessoas, uma vez que socializam espaços na comunidade, determinam quais cidadãos vão acessar os benefícios e medeiam aspectos da relação Estado-sociedade. Assim, os BNR são “lócus da ação 
pública, [pois são] os responsáveis pela mediação das relações cotidianas entre o Estado e os cidadãos" (LOTTA, 2015, p.44)

Olhar para a atuação desses burocratas implica em olhar também para as formas como eles constroem suas ações. Por um lado, essas ações são conformadas pelas normas e regras institucionais e, por outro, são fundamentadas em crenças e valores individuais. Esse segundo aspecto é denominado pela literatura como exercício da discricionariedade, percebido quando os burocratas determinam a natureza, a quantidade e a qualidade dos benefícios/sanções. Embora haja regras e normas que moldem alguns padrões de decisão, ainda assim, o BNR possui certa "autonomia para decidir como aplicá-las e inseri-las nas práticas da implementação" (LOTTA, 2015, p. 46).

$\mathrm{Na}$ área da educação, os professores são os principais agentes implementadores das políticas formuladas, pois eles são a ponta da cadeia de implementação. São eles que estão em contato direto com os estudantes beneficiários do serviço. É o professor, dentro de sala de aula, que cria as oportunidades didático-pedagógicas para que a aprendizagem aconteça. Em outras palavras: é o professor quem medeia o processo de aprendizagem dos estudantes. Nesse sentido, o professor é definido como o BNR, pois é ele o agente responsável pela garantia do aprendizado. De forma breve e sucinta, pode-se dizer que os professores prestam o serviço ${ }^{3}$ aos beneficiários da política

Entretanto, essa definição nem sempre se aplica de forma tão restrita e exata ao campo da educação. Primeiro, porque há uma série de políticas, cujo beneficiário não é, necessariamente, o estudante. Há casos, por exemplo, em que beneficiário das políticas de formação continuada é o professor. Segundo, porque não é somente o docente o responsável pela aprendizagem dos estudantes. Há outros burocratas atuando no nível da escola, como o diretor e o coordenador pedagógico, que, se não são responsáveis, são, pelo menos, corresponsáveis pela garantia do aprendizado.

\footnotetext{
${ }^{3}$ Nesta breve resenha, defino a aprendizagem - ou melhor, o processo ensino-aprendizagem, como o serviço que a educação entrega ao usuário da política. Uma discussão pertinente é se a aprendizagem é o único serviço a ser prestado. Pode-se ter uma definição mais ampliada sobre isso. Por exemplo, pode-se considerar que o acesso e a permanência na escola também se definem como um serviço da educação. Embora isso seja indiscutivelmente relevante, compreendo que o escopo do serviço educacional é a aprendizagem.
}

Revista Educação Online, Rio de Janeiro, n. 31, mai-ago 2019, p. 1-9 
Assim, no campo da educação, a definição do BNR deve levar em consideração o mapeamento de quem são os agentes educacionais responsáveis pelo aprendizado. Não há dúvidas de que o professor é o principal desses agentes, mas é somente ele? Ou outros agentes - diretores de escolas, coordenadores pedagógicos etc. - podem ser definidos como BNR? Ou seriam esses agentes burocratas de médio escalão?

O burocrata de médio escalão é aquele que faz o elo entre o alto escalão e os executores das políticas públicas (o BNR). São eles que conectam as fases de formulação e de implementação e fazem com que as políticas sejam colocadas em prática. Fazem parte dessa burocracia os gerentes, dirigentes, supervisores e agentes, cuja função é operacionalizar as estratégias que o alto escalão da burocracia formula (LOTTA; PIRES; OLIVEIRA, 2015), por meio da coordenação da atuação do BNR.

Se, por um lado, não se tem dúvidas de que o professor é um BNR, o mesmo não acontece quando se pensa no papel e atuação dos diretores escolares e de sua equipe. Essa definição, ao meu ver, depende do objeto da política que está sendo analisada. O primeiro passo é identificar o beneficiário e, a partir disso, identificar o agente do Estado responsável pela entrega do serviço ao beneficiário. Esse agente será o BNR.

Tal questão, coloca em voga outra temática que deve ser discutida nos estudos que se apropriam dessa literatura para a investigação de políticas educacionais: considerando que a maioria ${ }^{4}$ das políticas no campo da educação tem como finalidade principal a garantia do aprendizado dos estudantes, devese considerar o aprendizado como escopo do serviço prestado pelas políticas educacionais?

Explico-me: a maioria das políticas formuladas no campo da educação tem o objetivo principal de garantir o aprendizado dos estudantes. Uma política de formação continuada, como o Programa Nacional de Alfabetização na Idade Certa (Pnaic), por exemplo, destina-se aos professores alfabetizadores aqueles que estão na sala de aula, ministrando aulas para o ciclo de alfabetização. São eles os beneficiários da política. Entretanto, essa política foi

\footnotetext{
${ }^{4}$ Algumas políticas, como o Transporte Escolar e a Merenda Escolar, não têm como escopo o aprendizado, mas o beneficiário é o estudante.
}

Revista Educação Online, Rio de Janeiro, n. 31, mai-ago 2019, p. 1-9 
formulada com o objetivo de atender à meta 5 do Plano Nacional de Educação (PNE), que versa sobre a consolidação da alfabetização das crianças até o $3^{\circ}$ ano do ensino fundamental. Embora o usuário da política seja o professor e o BNR seja o formador local - profissional que dá a formação aos professores alfabetizadores -, o efeito da política se verifica pelo aprendizado - mensurado como desempenho pela Avaliação Nacional da Alfabetização (ANA). Oferece-se formação continuada com o objetivo de garantir a consolidação da alfabetização. A política se destina, portanto, ao professor alfabetizador, mas seu objetivo é beneficiar o estudante.

Dessa forma, uma reflexão que precisa ser colocada para a investigação no campo da educação é: mesmo que a política não tenha como beneficiário direto e imediato o estudante, é preciso considerar se a política gera, de alguma forma, benefício para os estudantes, uma vez que a aprendizagem é o escopo (LOTTA, 2015) do serviço educacional. Nesse sentido, acredito que os estudos que aderem à abordagem bottom-up e colocam o foco analítico na ação discricionária dos agentes implementadores devem considerar os benefícios que o serviço da política gera para os estudantes, ainda que o objeto da política não seja, necessariamente, a aprendizagem e o seu beneficiário direto não seja 0 estudante.

\section{Referências bibliográficas}

LOTTA, G. Burocracia e implementação de políticas públicas - os agentes comunitários na Estratégia Saúde da Família. Rio de Janeiro: Editora Fiocruz, 2015.

LIPSKY, M. Street-level bureaucracy, 30th ann. Ed.: dilemmas of the individual in public service. New York: Russell Sage Foundation, 2010.

LOTTA, G., PIRES, R., OLIVEIRA, V. Burocratas de médio escalão: novos olhares sobre velhos atores de políticas públicas. In: CAVALCANTE, P. LOTTA, G. (Orgs.). Burocracia de médio escalão: perfil, trajetória e atuação. Brasília: ENAP, 2015. p. 23-55 